\title{
Speech education of students with hearing impairment as a means of communication
}

\author{
Natalia Grash ${ }^{1}$, Marina Skuratovskaya ${ }^{2 *}$, and Elena Mamedova ${ }^{1}$ \\ ${ }^{1}$ The Herzen State Pedagogical University of Russia, 197046, St. Petersburg, Russia \\ ${ }^{2}$ Don State Technical University, 344000, Rostov-on-Don, Russia
}

\begin{abstract}
The article discusses the issue of teaching students with hearing impairment as a means of communication. The scientific-theoretical and applied aspects of the study of oral and written speech of children with intact and deficient hearing are revealed. The results of many years of research are considered and the existing psychological and pedagogical difficulties in language acquisition of students with auditory dysfunction are analyzed. The article focuses on the variable types of epistolary works that implement the communicative function. The importance of digital technologies in increasing the motivation for learning of the deaf and hard of hearing students and the effectiveness of the development of their written language in the educational process is emphasized. Attention is drawn to the positive result of using electronic educational resources in educational practice, which significantly expand the general cultural and speech zones of schoolchildren. The article indicates the importance of mastering by students with hearing impairment new skills and abilities of digital reading and writing as modern types of verbal written communicative form of speech.
\end{abstract}

\section{Introduction}

In the digital age, the problem of speech development among students with hearing impairment is of particular importance. Without the ability to write / type correctly, read and understand what has been written, verbally express their thoughts, it becomes extremely doubtful to fully master and use IT developments in the educational process by deaf and hard of hearing students.

In Russian defectology, the speech characteristics of deaf and hard of hearing students have been studied in detail. For them, the underdevelopment of all components of speech is typical: diverse violations in sound pronunciation, a scanty volume of vocabulary, the specific use of parts of speech, the use of vocabulary in excessively narrow or unjustifiably wide meanings, the originality of the grammatical structure, and so on. Significant problems are also present in written speech, which largely reflects the peculiarities of the oral speech of the deaf and hard of hearing, as it proceeds in conditions of extremely limited speech practice, almost simultaneously and in parallel with the teaching of oral speech.

\footnotetext{
* Corresponding author: marinasku@yandex.ru
} 


\section{Theoretical Basis}

Written speech is considered by Russian and foreign scientists from the point of view of neuropsychology, psychology, psycholinguistics: B. G. Ananiev, L. S. Vygotsky, A. R. Luria, S. L Rubinstein, Rim S. V. Alyakhya, Ajay D. Halai, Matthew A. Lambon Ralph, David Kaplan, Gloria Waters, Amanda Reddy, Max Coltheart [1-7] and many others. The authors' studies prove that the psychological level solves the problems of forming motives, interest in written speech, semantic content of information, regulates and controls the activity of writing and is realized through the work of the frontal parts of the brain.

The linguistic level of organization of written speech is responsible for translating thoughts into words, phrases and monologic statements and is carried out through the interaction of Broca's anterior speech zone and Wernicke's posterior speech zone. At the psychophysiological level, the joint work of several analyzing systems is implemented, which underlie written speech. This is the interaction of speech-motor, auditory, opticalspatial and motor analyzers of the brain.

A number of studies [2, 3, 8, 9] analyze the prerequisites for the formation of written speech in children with preserved hearing. First, the formation of oral speech, voluntary mastery of it, the ability for analytical and synthetic speech activity is necessary. Secondly, the formation and interaction of different types of sensations, perceptions and knowledge plays an important role. Thirdly, the development of the motor sphere, fine motor skills and object actions. Fourth, the completeness of abstract methods of activity. This is possible only when the child gradually transfers from actions with concrete objects to actions with abstractions. Fifth, the formation of general speech behavior.

Interesting data is presented in the works of B. G. Ananyeva, L. S. Vygotsky, A. A. Leontiev, A. R. Luria, Rim S. V. Alyakhya, Ajay D. Halai, Matthew A. Lambon Ralph, David Kaplan, Gloria Waters, Amanda Reddy, Max Coltheart [1-3, 5, 6, 7, 9], which most fully explains the psychological and psycholinguistic characteristics of written speech. Scientists note that written speech is a special speech process that is consciously formed in the learning process. This is abstract speech without an interlocutor, which in its structure represents grammatically organized detailed statements and requires a high level of abstraction, because it is only thought, not uttered. Written speech is a special form of communication using a system of written signs, which is implemented in various genres: epistolary production, diary entries, literary creation. It differs from oral speech in special stylistic norms, a complex system of punctuation rules, the absence of means of conveying emotional coloring and a prosodic component.

The authors point out that written speech is a specific form of displaying the content of oral speech and plays an important role in the formation and development of verbal-logical thinking $[1-7,9]$. It provides conscious control over the ongoing mental operations, allows you to repeatedly refer to what has already been written, transmit not only ready-made information, but also clarify your own thoughts, and work out the content of the text.

The concept of "written speech" includes the concepts of "reading" and "writing". A. A. Leontiev, A. R. Luria, S. L. Rubinstein, Max Coltheart $[9,3,4,7]$ consider reading as a specific type of human activity that activates his cognitive activity, has a beneficial effect on the formation of the worldview and personality, on social behavior and social activity, preserves and transfers socio-historical experience humanity. Attention is also drawn to the fact that writing is a complex, conscious type of speech activity that has similarities and differences with oral speech. These differences are associated with the origin, ways of formation, course, psychological content and functions of the writing process. The writing process first acts as a deliberate action, and only gradually becomes a skill. This is the difference between written speech and external speech, which is formed involuntarily and proceeds automatically. Written speech includes several special operations. First, it is the 
analysis of the sound composition of the word that needs to be written down. Secondly, this is the translation of phonemes into graphemes, taking into account the spatial arrangement of their elements. Thirdly, this is the "re-decoding" of the visual schemes of letters into a kinetic system of sequential movements necessary for recording. One of the most difficult operations is the analysis of the sound structure of a word, when a child first needs to determine the sequence of sounds in a word, and then turn the audible sound variants into phonemes. In this process, speech-auditory and speech-motor analyzers play a decisive role. At the stage of translating phonemes into graphemes, it is required to correlate the phoneme extracted from the word with a certain visual differentiated image of the letter. The difficulties that students face in the initial stages of learning to write are the insufficient level of formation of visual analysis and synthesis, spatial representations, analysis and comparison of letters. The last operation of the writing process is motor reproduction with the help of hand movements of the visual image of the letter in the kinema. At this stage, kinesthetic and visual controls are carried out.

The foregoing allows us to say that the writing process is least of all a simple "ideomotor" act. It includes many mental processes that lie both outside the visual sphere, which is associated with the representation of letters, and outside the motor sphere, which directly implements the writing process. These facts indicate that the writing process is carried out on the basis of a sufficient level of formation of certain speech and non-speech functions: auditory differentiation of sounds, their correct pronunciation, language analysis and synthesis, the formation of the lexical and grammatical side of speech, visual analysis and synthesis, spatial representations.

Written speech differs fundamentally from oral speech in its structure. A. A. Leontiev, A. R. Luria, S. L. Rubinstein $[9,3,4]$ distinguish phonemic, lexical and syntactic levels in written speech, that are not present in oral speech. The phonetic level consists in the selection of individual sounds, in their opposition, the coding of individual sounds into letters, the combination of individual sounds and letters into words. The lexical level consists of the selection of words, the search for suitable and necessary verbal expressions and opposing them to other lexical alternatives. The syntactic level is reduced to the conscious construction of a phrase, which is mediated by the available speech skills, the rules of grammar and syntax necessary to make the content of written speech understandable in the absence of accompanying gestures and intonations.

The data presented in the studies of Russian and foreign scientists are important: L. M. Bykova, R. M. Boskis, N. E. Grash, A. G. Zikeev, S. A. Zykov, M. I. Nikitina, Eliza Mohanti, Anindya Jayantha Mishra, Linda J. Spencer, Mark Marshark, Carol Convertino, Jorin A. Vermeulen, Eddie Denessen, Harry Noors, Nadina Gomez-Merino, Inmaculada Fajardo, Antonio Ferrer [10-16]. The authors emphasize the crucial role of hearing in the mental and psychological development of a child. Inadequacy of auditory sensations and perceptions, lack of formation of auditory ideas entail a delay in the development of speech and verbal-logical thinking, deprive the child of full-fledged assimilation of knowledge and means of communication.

\section{Results}

In Russian deaf education, language teaching of children with hearing impairment is carried out within the communicative system and proceeds in three directions: the development of language ability, the development of all types of speech activity, the assimilation of the systemic nature of the language.

The development of language ability first consists of the formation of a psychophysiological mechanism of perception, understanding, reproduction and production of speech discourses, in the development of reading and writing skills, in the ability to 
independently create new statements according to familiar models, to selectively use forms of speech depending on the real conditions of communication. Later, linguistic ability begins to be realized in the increasingly complex conditions of speech communication, when students must arbitrarily change speech material, expand or complete dialogues, maintain the topic of conversation or change it taking into account the interests of the interlocutors, widely use synonymous modifications of discourses, motivate correct and erroneously constructed offers. At the final stage of training, the language ability develops to the linguistic level, determining the knowledge of the methods of inflection and word formation, the rules for combining words and using speech models.

The development of all types of speech activity in the initial period of language learning consists in mastering by schoolchildren the skills of fingerprinting, auditory perception, speaking, reading, writing. Later, students master the ability to describe objects and events, learn variable types of epistolary work, improve their pronunciation skills, visual reception of familiar and new speech materials, visual perception of speech from the face. The systematic use of individual hearing aids contributes to the development of auditory speech perception, bringing the speed and automatism of all speech skills closer to the norm, which ensure the functioning of the language.

Work on mastering the systemic nature of the language at the initial stage of training is minimal. It boils down to the ability of children to distinguish between questions and answers, instructions and messages on the results of actions in real communication conditions. As schoolchildren accumulate speech means, the development of affirmative and negative constructions of sentences begins, which contribute to the assimilation of basic word forms. Later, high school students begin to study all sections of the Russian language that contain its systematic description, perform various types of grammatical analysis, master the definitions of all grammatical concepts, and begin to use generally accepted terminology.

Language teaching of schoolchildren with auditory dysfunction takes into account the originality of speech development, deviations in the phonetic structure of speech, the peculiarities of mastering the vocabulary of the language and the grammatical structure of speech, the specifics of writing and understanding of addressed speech.

Lots of studies have analyzed the most common mistakes in the speech of students with hearing impairment [10-12]. These include violations of the phonetic composition of a word: replacing some sounds with others, distorting the sound composition of a word, missing one sound / letter or syllable, missing a consonant sound in a consonant combination, writing extra letters, replacing or rearranging letters. Even slight difficulties in the clarity of the sound-letter analysis of words lead to the above deviations. The reasons for such errors are, first of all, a deep disturbance in the activity of the auditory analyzer, when an inadequate perception of a word by ear leads to its distorted assimilation without a clear division into constituent sound elements.

Deaf and hard of hearing students are characterized by a discrepancy between knowledge of grammar and real practical speech skills and abilities. Students with hearing impairments simplify the grammatical structure of the language and use a more limited number of grammatical means in their speech than they know [10-12]. This simplification is expressed in the "approximate" grammatical design of speech, which is often accompanied by incorrect use of various parts of speech, incorrect use or omission of prepositions, aberrational use of endings, errors in form formation, in the construction of phrases, omission or introduction of unnecessary members of the sentence, the use of unnecessary conjunctions, incorrect using personal pronouns and so on.

Lexico-phraseological errors include: incorrect choice of a word, distortion of the sound composition of a lexeme, aberrations in a combination of words in a sentence, omission of lexemes in a sentence, confusion based on semantic contiguity. Characteristic for the deaf 
and hard of hearing are the contamination of parts of speech, the agrammatical use or use of unnecessary prefixes and suffixes, the inability to correctly use synonyms and paraphrases, violations in the semantics of verbs, especially when operating with temporal forms.

In the process of teaching the language and the development of verbal-logical thinking of students with hearing impairment, there is a positive trend towards an increase in the use of adjectives, adverbs, and pronouns in speech. At the same time, it is noted that in the oral and written speech of students, there are practically no participles and participles.

A number of authors note that deaf and hard of hearing senior pupils have shortcomings in the stylistic design of written texts [10-15]. They are expressed in limited or excessive lexical filling of sentences, frequent mixing of derived lexemes with the original ones, which distorts the derivational meaning of words.

As noted by L. M. Bykova, R. M. Boskis, N. E. Grash, M. I. Nikitina, Eliza Mohanti, Anindya Jayantha Mishra, Linda J. Spencer, Mark Marshark, Carol Convertino, Jorin A. Vermeulen, Eddie Denessen, Harry Noors, Nadina Gomez-Merino, Inmaculada Fajardo, Antonio Ferrer [10-16] deaf and hard of hearing students when reading. Natural obstacles in the understanding of readable texts for this category of schoolchildren are: a sharply limited vocabulary, insufficient mastery of the grammatical structure of speech, not formed skills of correct, fluent, conscious, expressive reading, poor command of methods of reading aloud and to oneself, analytical and synthetic mental processing of content works, the mechanisms of its perception. So, meeting familiar vocabulary in the text, but in a different grammatical form, variability in the use of pronouns and prepositions, as a rule, lead to the fact that readers with hearing impairments misinterpret their meanings or do not recognize them at all. Lack of understanding of the meaning of grammatical forms, limited vocabulary, lack of knowledge of variable vocabulary and phraseology, inability to use familiar synonyms and paraphrases, lack of knowledge of the contextual meaning of vocabulary, lack of understanding of the ambiguity of words and much more becomes a serious obstacle to full perception and comprehension by the deaf and hard of hearing even the easiest and most accessible software the content of the text. As a result, many students read little and reluctantly, and categorically do not want to read on their own. As a result, they do not develop an interest in this type of speech activity.

The peculiarity of the reading of the deaf and hearing impaired is due both to the general tendencies of initial reading, typical for hearing children, and to the peculiarities inherent in this category of students. General tendencies include: letter-by-letter character of reading, difficulties in fusing sounds into syllables, slow tempo, multiple breaks in the reproduction of letters, returns to the beginning of a word, difficulties in retaining the sequence of reproduction of sounds-letters in memory and correlating them with the syllable sample of a whole word. Specific features are: deep hearing impairment, general speech underdevelopment, contamination (mixing) of sounds-letters, loss of sounds from a word, permutation (rearrangement) of sounds and syllables, false associations when guessing parts of a word or its coherent image, features of the formation of thought processes.

Table 1. Specific reading errors.

\begin{tabular}{|c|c|c|}
\hline № & Types of read errors & The essence of mistakes \\
\hline 1. & Pronunciation errors & $\begin{array}{l}\text { all kinds of distortions; incorrect emphasis in } \\
\text { familiar words }\end{array}$ \\
\hline 2. & $\begin{array}{l}\text { Failure to comply with } \\
\text { spelling rules }\end{array}$ & $\begin{array}{l}\text { do not miss unpronounceable consonants; do not } \\
\text { deafen consonants at the end of words }\end{array}$ \\
\hline 3. & Poor reading skills & $\begin{array}{l}\text { stretch syllables; find it difficult to consistently } \\
\text { pronounce syllables in words; parts of words and } \\
\text { whole words are skipped; rearrange sounds }\end{array}$ \\
\hline
\end{tabular}




\begin{tabular}{|c|c|c|}
\hline 4. & $\begin{array}{c}\text { Errors of visual perception of } \\
\text { the text }\end{array}$ & $\begin{array}{c}\text { repetitions; rotation of words according to the } \\
\text { similarity of the visual image; do not distinguish } \\
\text { between cognate lexemes }\end{array}$ \\
\hline 5. & $\begin{array}{c}\text { Inability to use the prosodic } \\
\text { characteristics of the language }\end{array}$ & $\begin{array}{c}\text { do not change the pitch of voice intonations; do } \\
\text { not differentiate intonation differences at an } \\
\text { unconscious practical level; } \\
\text { do not use emotionally - intuitive placement of } \\
\text { semantic pauses; replace the interrogative } \\
\text { intonation of the narrative with the same voice } \\
\text { strength; can't keep up with the pace of the story }\end{array}$ \\
\hline
\end{tabular}

As studies show [10-16], the features of the reproduction and interpretation of texts by the deaf and hard of hearing are closely related to the specifics of the formation of their verbal-logical thinking. The impossibility or atypical nature of the timing of the natural formation of speech in these children leads to the fact that they, especially at the start of learning, "get stuck" at the stage of visual-figurative thinking. Therefore, it is very difficult for schoolchildren to determine the cause-and-effect relationships, motives and significance of the characters' actions. They focus on insignificant but familiar everyday details. The author's typicality of the circumstances in which the typified literary hero acts is overlooked. Students think not in generalized concepts, but in concrete visual images. Often these images do not correspond to the author's intention. This leads to a misunderstanding of the meaning of the reading. A serious problem for the deaf and hard of hearing is the retelling of the content of what they read in their own words. Pupils strive for verbatim reproduction of the text, because the sharply limited speech module does not allow children to be distracted from the specific meaning of the word.

\section{Discussion}

The presented data indicate that the main task in modern schools for the deaf and hard of hearing remains the task of language teaching. Speech work is organically included not only in every language lesson, but also in all other academic subjects. They work to improve and develop the skills of oral and written speech of schoolchildren on the basis of expanding knowledge about the surrounding reality in close connection with the development of cognitive activity [10-16]. The motivation for such types of speech activities as writing and reading, which are methods of indirect communication in the absence of a direct interlocutor, is gradually increasing. It becomes important to enrich the skills of communication and arbitrary choice of speech means due to the awareness of linguistic meanings. Compared to the elementary grades, the volume of work on teaching written independent speech is increasing. Much attention is paid to performing tasks that implement the communicative function of speech and are aimed at the practical application of the knowledge gained: writing letters, notes, various reports, business papers, notes, announcements, notifications, receipts, statements, autobiography, filling out questionnaires, forms for a parcel. It is important that teaching any of these types of work is carried out without relying on dialogical speech [10-12]. It is these types of written language that young people with hearing impairments will need in later life. All these coherent statements have their addressee, and, therefore, work on them is motivated, which increases interest in its implementation, activates thinking and speech activity. The task is not only to teach students to work with official papers and documents, to build a detailed monologue about their needs, experiences, impressions, but also to successfully understand printed texts. Therefore, mastering the written form of speech acts as a means of 
compensating for the consequences of hearing impairment and leads to an expansion of communication with others.

Invaluable help in solving this issue at the present stage of education development, as emphasized by Jef Peeraer, Peter Van Petegem, Ceyda Ilgaz Büyükbaykal, Farida BouarabDahmani, Razika Tahi, Federica Cornali, Simona Tirocchi, Pablo Sánchez-Antolín, Francisco Javier Ramos, Montserrat Blanco-García [17-22], provide information and communication technologies, which are increasingly being introduced into the educational process. With the observance of the necessary health-saving measures in schools for children with hearing impairments, they help to solve urgent educational tasks at a fundamentally higher level, improve the quality of educational material, variability of forms of work with students, and enhance the educational effect [10]. Information and communication technologies in the form of electronic educational resources offer additional opportunities for the individualization of the productive activity of deaf and hard of hearing students, the development of their speech and cognitive potential, and creative abilities.

The issues of using electronic educational resources in the modern educational process are the subject of research by many Russian and foreign scientists: G. A. Bordovsky, I. B. Gotskaya, S. A. Zhdanova, S. P. Ilyina, V. I. Snegurova [23], Jef Peeraer, Peter Van Petegem, Ceyda Ilgaz Büyükbaykal, Farida Bouarab-Dahmani, Razika Tahi, Federica Cornali, Simona Tirocchi, Pablo Sánchez-Antolín, Francisco Javier Ramos, Montserrat Blanco-García [17-22] "Electronic educational resources" are considered by the authors as a set of software, technical and organizational support, educational, methodological, reference and other information necessary for the effective organization of educational activities, which are developed and reproduced on the basis of computer technology. Electronic educational resources present educational and developmental information in a more accessible and visual form and give students the most complete understanding of the subjects, processes and phenomena being studied. The intact visual analyzer of deaf and hard of hearing schoolchildren performs one of the leading compensatory functions in the learning process. Therefore, electronic educational resources have great motivating potential. Students with hearing impairments enjoy using modern information and communication technologies in their educational activities, which provide them with much faster and more information than traditional sources. They contribute to the formation of motivation for learning activities and the activation of the cognitive sphere of students. They increase the possibilities of modeling the subject content of complex objects of study hidden from direct observation. Increase the efficiency of frontal and individual work. They create additional visual dynamic types of assistance for students to analyze their own activities in real and prolonged time.

The use of electronic educational resources and teaching computer programs in subjects allows the teacher to move from an explanatory-illustrative teaching method to an activitybased one. Deaf students become controversial subjects of the learning space, their cognitive sphere is activated, they begin to more consciously assimilate the material. Electronic educational resources help students understand the flow of new thematic information: get acquainted and study it, update and consolidate the material, practice speech skills and abilities, generalize and systematize knowledge.

The use of computers and various gadgets in educational institutions for people with hearing impairment is impossible without high-quality reading skills and abilities in schoolchildren as a type of speech activity. Therefore, one of the important issues is the mastery of students in digital reading, which increases the motivation to learn. O. N. Borisenko [24], Yu. P. Melentieva [25], Jason Merkoski [26] consider "digital reading" as reading texts that have undergone digital processing and placed on electronic media. Researchers D. J. Lew, L. Zawilinski, J. Castek, M. Banerjee, D. B. Housand, Y. Liu, Charles K. Kinzer, D. Coiro, Jill Castek, Laurie A. Henry, N. Carr [27, 28, 29] confirm that 
digital reading is becoming a daily activity for young people. She uses it in everyday life for personal communication, searching for information, reading fiction, electronic textbooks, online learning.

People with hearing impairment are no exception. Most students combine digital and paper reading $[23,24]$. But classical reading is confidently shifting to digital format. Helen Blom, Eliane Segers, Ludo Verhoeven, Ines Kožuh, Manfred Hintermair, Matjaž Debevc confirm that deaf and hard of hearing high school students are active participants in social networks. They organize groups, communities, discussions, read static texts, news, entertainment, advertising websites from the screens of computers, laptops, tablets, smartphones, interactive texts on the Internet, use hyperlinks [30, 31, 32]. However, today young people with auditory dysfunction are learning the new reading format spontaneously. The school has practically no relation to the formation of this skill and its quality. Therefore, the urgent task of the modern educational process is the purposeful teaching of students with hearing impairment in digital reading and writing as new types of written communicative form of speech $[33,34]$.

\section{Conclusion}

Our analysis of the psychological and pedagogical aspects of the formation and development of oral and written speech of deaf and hard of hearing students shows the undoubted relevance and importance of this issue. Modern research studies the specifics of all speech components of students with hearing impairments. They are engaged in the formation, development and correction of speech activity of the deaf and hard of hearing, so that it can fully act as a means of communication. But no less important areas of work are the search and use of modern effective approaches to the learning process, increasing the educational motivation of schoolchildren, mastering new types of written communication, strengthening the meaningful, effective, entertaining, variable components of education. One of these innovations is the recovery of information and communication technologies in the educational process of people with hearing impairments. An equally important aspect is the professional readiness of teachers to competently implement and rationally combine traditional educational tools with modern information and computer foresights. Such a dosed, compromise set of innovative and classic digital technologies today is beginning to take shape as one of the ways to solve the problem of modernizing special education. It becomes a new way of transferring knowledge, concretizing educational and spontaneous stimuli, expanding the boundaries of the information field of the deaf and hard of hearing, developing cognitive activity, the aesthetic sphere and the general cultural outlook of this category of students.

\section{References}

1. B.G. Ananiev, Man as a subject of knowledge (Peter, St. Petersburg, 2010).

2. L.S. Vygotsky, Thinking and speech (Peter, St. Petersburg, 2017).

3. A.R. Luria, Lectures on general psychology (Peter, St. Petersburg, 2018).

4. S.L. Rubinstein, Fundamentals of General Psychology (Peter, St. Petersburg, 2010).

5. S.W. Reem, Alyahya, D. Halai Ajay, A. Lambon Ralph Matthew, NeuroImage: Clinical 18, 215-230 (2018). ,https://doi.org/10.1016/j.nicl.2018.01.03

6. David Caplan, Gloria Waters, Amanda Reddy, Brain and Language May 101 (2), 103150 (2007). https://doi.org/10.1016/j.bandl.2006.06.225 
7. Max Coltheart, Cortex 42 (6), 855-860 (2006). https://doi.org/10.1016/S00109452(08)70428-3

8. L.S. Tsvetkova, A.V. Tsvetkov, Book publishing com, Moscow, (2021).

9. A.A. Leontiev, Language, speech, speech activity (Lenand, Moscow, 2014).

10. O.A. Krasilnikova, G.N. Penin, L.V. Korableva, M.I. Nikitina, N.E. Grash, E.Y. Mamedova, and others, Publishing house of the Russian State Pedagogical University named after A.I. Herzen, St. Petersburg, (2018).

11. N.E. Grash, Publishing house RSPU im. A.I. Herzen, St. Petersburg, 84-88 (2019).

12. A.G. Zikeev, Speech development of students of special correctional educational institutions (Academy, Moscow, 2007).

13. Elisa Mohanty, Anindya Jayanta Mishra, Alter 14 (2), 85-98 (2020). https://doi.org/10.1016/j.alter.2020.02.002

14. Linda J. Spencer, Marc Marschark, Carol Convertino, Journal of Communication Disorders 75, 13-24 (2018). DOI: 10.1016/j.jcomdis.2018.06.002

15. Jorine A. Vermeulen, Eddie Denessen, Harry Knoors, Teaching and Teacher Education 28 (2), 174-181 (2012). DOI: 10.1016/j.tate.2011.09.007

16. Nadina Gómez-Merino, Inmaculada Fajardo, Antonio Ferrer, Research in Developmental Disabilities 112, 103908 (2021). DOI: 10.1016/j.ridd.2021.103908

17. Jef Peeraer, Peter Van Petegem, Evaluation and Program Planning 48, 47-56 (2015). DOI: 10.1016/j.evalprogplan.2014.09.005

18. Ceyda Ilgaz Büyükbaykal, Procedia - Social and Behavioral Sciences 174, 636-640 (2015). DOI: 10.1016/j.sbspro.2015.01.594

19. Jef Peeraer, Peter Van Petegem, Computers \& Education 58 (4), 1247-1259 (2012). DOI: 10.1016/j.compedu.2011.12.015

20. Farida Bouarab-Dahmani, Razika Tahi, Procedia - Social and Behavioral Sciences 174, 602-608 (2015). DOI: 10.1016/j.sbspro.2015.01.589

21. Federica Cornali, Simona Tirocchi, Procedia - Social and Behavioral Sciences 47, 2060-2069 (2012). DOI: 10.1016/j.sbspro.2012.06.949

22. Pablo Sánchez-Antolín, Procedia - Social and Behavioral Sciences 116, 1519-1522 (2014). DOI: $10.1016 /$ j.sbspro.2014.01.427

23. G.A. Bordovsky, I.B. Gotskaya, S.P. Ilyina, V.I. Snegurova, Publishing house of the Russian State Pedagogical University named after A.I. Herzen, St. Petersburg, (2007).

24. N.A. Borisenko, ChGIK, Chelyabinsk, 291-296 (2019).

25. Y.P. Melentieva, Scientific and Publishing Center "Science" of the Russian Academy of Sciences, Moscow, 5 (418), 47-51 (2018).

26. Jason Merkoski, Sourcebooks, Inc. и Nova Littera SIA, (2014). DOI: 10.1007/s12109014-9351-x

27. D.J. Leu, L. Zawilinski, J. Castek, M. Banerjee, D.B. Housan, Liu, What is new about the new literacies of online reading comprehension? In L. Rush, J. Eakle, \& A. Berger (Eds.), Secondary school literacy: What research reveals for classroom practices. National Council of Teachers of English, Urbana, IL, 37-68 (2007). DOI: 10.1080/19388071.2016.1135388

28. Donald J. Leu, Charles K. Kinzer, Julie Coiro, Jill Castek, Laurie A. Henry, Connecticut; Teachers College, Columbia University; University of Rhode Island; Portland State University; University of Kentucky 197 (2), 1-18 (2017). DOI: $10.1598 / 0710.42$ 
29. Carr Nicholas, The Shallows: What the Internet Is Doing to Our Brain (W. W. Norton Company, London, 2011). DOI: 10.1080/01972243.2013.758481

30. Helen Blom, Eliane Segers, Ludo Verhoeven, Research in Developmental Disabilities 61, 127-137 (2017). DOI: 10.1016/j.ridd.2016.12.014

31. Helen Blom, Eliane Segers, Ludo Verhoeven, Learning and Individual Differences 73, 124-137 (2019). https://doi.org/10.1016/j.lindif.2019.05.006

32. Ines Kožuh, Manfred Hintermair, Matjaž Debevc, Computers in Human Behavior 65, 295-307 (2016). https://doi.org/10.1016/j.chb.2016.08.035

33. M. Skuratovskaya, E. Romanova, E3S Web of Conferences 210, 18103 (2020). https://doi.org/10.1051/e3sconf/202021018103.

34. Natalia Berdnikova, Natalia Abashina, E3S Web of Conferences 210, 18001 (2020). ITSE-2020. https://doi.org/10.1051/e3sconf/202021018001. 